ISSN 0103-9954

\title{
SISTEMA DE APOIO À GESTÃO DE ÁREAS VERDES NA PRESERVAÇ̃̃O PERMANENTE DE CORPOS HÍDRICOS URBANOS
}

\author{
SUPPORT SYSTEM FOR MANAGEMENT OF GREEN SPACES IN PERMANENT \\ PRESERVATION OF URBAN WATER BODIES
}

\author{
Adriano Bressane $^{1}$ Patricia Satie Mochizuki ${ }^{2}$ José Arnaldo Frutuoso Roveda ${ }^{3}$ \\ Nemésio Neves Batista Salvador ${ }^{4}$
}

\begin{abstract}
RESUMO
A conservação de áreas verdes urbanas está entre as principais estratégias para o alcance de cidades saudáveis e sustentáveis. Entretanto, a multiplicidade de critérios envolvidos requer uma análise integrada por meio de um procedimento lógico e estruturado. Portanto, este artigo tem como objetivo apresentar a proposta de um sistema de suporte à decisão para gestão de áreas verdes de domínio público em áreas de preservação permanente de corpos hídricos urbanos. Para o seu desenvolvimento foram adotadas as diretrizes do método de planejamento por cenários, mediante o qual foram analisados aspectos correlatos ao problema e encaminhamento de soluções. Os principais materiais utilizados corresponderam às obras da literatura técnica e a legislação aplicada, levantados através de termos de busca junto aos acervos bibliográficos e bancos normativos. A partir da análise destes materiais foram estudadas as efetivas funções das referidas áreas de preservação permanente e os fatores intervenientes ao seu desempenho e proteção. Como resultado, obteve-se um modelo estruturado em chaves de decisão para seleção de alternativas locacionais e de sua aptidão espaço-funcional.
\end{abstract}

Palavras-chave: suporte à decisão; área de preservação permanente; área verde de domínio público.

\begin{abstract}
The conservation of urban green areas is among the key strategies for achieving healthy and sustainable cities. However, the multiplicity of the involved factors requires an integrated analysis by means of a logical and structured procedure. Therefore, this article aims to present the proposal for a decision support system for the management of green areas in public domain, in areas of permanent preservation of urban water bodies. For its development, guidelines of the plannning method through scenarios were adopted, by which the aspects related to the problem and routing solutions were analysed. The main used materials correspond to the works of technical literature and legislation, raised through search terms along with bibliographic and legislative seats. From the analysis of these materials, we studied the actual functions of these areas of permanent preservation and the factors affecting their performance and protection. As a result, we obtained
\end{abstract}

1 Engenheiro Ambiental, Msc., Doutorando do Programa de Pós-graduação em Ciências Ambientais, Universidade Estadual Paulista, Av. 3 de março, 511, Alto da Boa Vista, CEP 18087-180, Sorocaba (SP), Brasil. adriano.bressane@posgrad.sorocaba.unesp.br

2 Engenheira Ambiental, Esp., Coordenadoria de Biodiversidade e Recursos Naturais, Secretaria do Meio Ambiente do Estado de São Paulo, Rua Gustavo Teixeira, 412, Mangal, CEP 18040-343, Sorocaba (SP), Brasil. patriciasm@ambiente.sp.gov.br

3 Matemático, Dr., Professor Assistente do Programa de Pós-graduação em Ciências Ambientais, Universidade Estadual Paulista, Av. 3 de março, 511, Alto da Boa Vista, CEP 18087-180, Sorocaba (SP), Brasil. roveda@sorocaba.unesp.br

4 Engenheiro Civil, Dr., Professor Titular do Programa de Pós-graduação em Engenharia Urbana, Universidade Federal de São Carlos, Rod. Washington Luis, km 235, Caixa Postal 676, CEP 13565-905, São Carlos (SP), Brasil. nemesio@ufscar.br

Recebido para publicação em 8/09/2011 e aceito em 13/11/2014

Ci. Fl., v. 26, n. 3, jul.-set., 2016 
a structured model in key decision for the selection of the location alternatives and their function-space capability.

Keywords: decision support; permanent preservation area; green area of public domain.

\section{INTRODUÇÃO}

O crescimento populacional e a ocupação desordenada em áreas urbanas têm se tornado uma constante nas cidades brasileiras de médio e grande porte, desencadeando problemas sociais e desequilíbrios ecológicos extremos (BRASIL, 2009). Como agravante, além da supressão significativa da cobertura vegetal (NUCCI e CAVALHEIRO, 1997), a inadequada gestão das áreas verdes urbanas remanescentes constitui um dos principais problemas para o alcance de cidades saudáveis e sustentáveis (MORENO, 2007).

Logo, considerando a importância das áreas verdes no meio urbano, a falta de uma abordagem sistematizada para sua adequada gestão pode comprometer a manutenção das características naturais destes espaços e, consequentemente, prejudicar suas funções ecológicas, a qualidade ambiental e o bem-estar da população (LOBODA, 2003; SARAIVA, 1999).

No entanto, a existência de múltiplos interesses configura frequentes conflitos no ordenamento territorial urbano, sobretudo, no que tange ao planejamento e controle do uso e ocupação do solo em áreas destinadas à proteção ambiental, tal como a preservação permanente de corpos hídricos (MACHADO, 2011).

Uma alternativa visando proporcionar uma melhor integração entre o ambiente natural, sobretudo no entorno de corpos hídricos, e o meio construído que predomina nas cidades, tem sido a implantação de parques lineares (FRIEDRICH, 2007).

Para disciplinar essa solução e, assim, conciliar a proteção ambiental à dinâmica do meio urbano, as áreas verdes de domínio público (AVDP) foram regulamentadas pela Resolução Conama $n$. 369 de 2006, segundo a qual essas áreas consistem no: "espaço de domínio público que desempenhe função ecológica, paisagística e recreativa, propiciando a melhoria da qualidade estética, funcional e ambiental da cidade, sendo dotado de vegetação e espaços livres de impermeabilização" $\left(\S 1^{\circ}\right.$, inciso III, artigo $\left.8^{\circ}\right)$.

Contudo, se não forem criteriosamente implementadas, tais áreas podem não atender a sua finalidade. Logo, o objetivo deste artigo é propor um sistema de suporte à decisão (SSD) para gestão de AVDP em áreas de preservação permanente (APP) de corpos hídricos urbanos.

\section{MATERIAL E MÉTODO}

O presente estudo corresponde à compilação dos principais resultados de uma pesquisa e dissertação de mestrado (BRESSANE, 2011). Para o desenvolvimento do SSD proposto foram executadas as etapas do método de planejamento por cenários, propostas por Schwarts (2006), sendo as quais: (1) definição do problema ou objetivo a ser alcançado; (2) identificação dos processos relevantes envolvidos no fenômeno estudado; (3) identificação dos fatores que influenciam os processos (fatores-chave); (4) definição de forçasmotrizes, possíveis decisões a serem tomadas; (5) classificação e definição de aptidão baseadas nos fatores selecionados; e (6) estruturação do processo decisório.

A definição do problema foi alcançada por meio do estudo e revisão da literatura aplicada, o que permitiu constatar a carência na sistematização de critérios. O estudo da legislação e das funções das APP possibilitou identificar os processos envolvidos e selecionar os principais fatores intervenientes ao seu desempenho. Na sequência, as ações durante o processo decisório foram definidas segundo os fatores analisados como critérios de seleção de alternativa locacional e de configuração espaço-funcional para a implantação da AVDP. Na etapa seguinte, foram definidos parâmetros para cada fator selecionado que, por sua vez, foram classificados como indicadores de:

- Restrição Absoluta (RA): impossibilita a seleção da alternativa locacional para implantação da AVDP;

- Aptidão Parcial (AP): possibilita a seleção da alternativa locacional, mas com uma configuração espaço-funcional que priorize as funções ecológicas da APP; e

- Aptidão Total (AT): possibilita a seleção da alternativa locacional com uma configuração 
espaço-funcional em que podem ser priorizadas as funções sociais da APP.

Por fim, o SSD foi estruturado através de chaves na forma de fluxogramas padronizados, segundo normativa da American National Standards Institute (ANSI, 1970).

\section{RESULTADOS E DISCUSSÃO}

\section{Síntese dos fatores normativos intervenientes a} implementação de AVDP

Com o agravamento das questões ambientais e suas consequências sobre a ocorrência de eventos extremos, como a escassez de água, tornou-se necessária uma visão holística para gestão dos recursos naturais (VICTORINO, 2002). Entretanto, ainda na fase considerada de exploração desregrada do direito ambiental brasileiro, na ausência desta perspectiva sistêmica foi decretado o Código das Águas, Decreto Federal n. 24.643 de 1934 (BENJAMIN, 1999). No que se aplica a AVDP, importa observar que esta norma determina que:

Art. 11. São públicos dominicais, se não estiverem destinados ao uso comum, ou por algum título legítimo não pertencerem ao domínio particular: $1^{\circ}$. os terrenos de marinha; $2^{\circ}$. os terrenos reservados nas margens das correntes públicas de uso comum, bem como dos canais, lagos e lagoas da mesma espécie. Salvo quando às correntes que, não sendo navegáveis nem flutuáveis, concorrem apenas para formar outras simplesmente flutuáveis e não navegáveis.

Portanto, ressalta-se como primeiro fator normativo que não constitui alternativas para localização de AVDP aquele sobre domínio particular sem prévia desapropriação do imóvel privado para fins de utilidade pública. Assim, esse condicionante pode representar uma limitação significativa em um cenário conflitante para efetividade da gestão e controle ambiental das áreas verdes (SILVA, SOUZA e LOUREIRO, 2001, BONONI, 2006). Outro fator estabelecido por esta norma diz respeito às faixas de servidão sobre as margens:

Art. 13. Constituem terrenos de marinha todos os que, banhados pelas águas do mar ou dos rios navegáveis, vão até 33 metros para a parte da terra, contados desde o ponto a que chega o preamar médio [...].

Art. 14. Os terrenos reservados são os que, banhados pelas correntes navegáveis, fora do alcance das marés, vão até a distância de 15 metros para a parte de terra, contados desde o ponto médio das enchentes ordinárias.

Portanto, na seleção de alternativas locacionais deve ser observada a condição de navegabilidade do curso hídrico em análise, respeitando, conforme o caso, as faixas de 10,15 ou 33 metros de servidão.

O novo Código Florestal promulgado pela Lei n. 12.651 de 2012, que revoga a normativa anterior, de 1965, manteve a previsão da AVDP, assim como a APP ao longo da hidrografia como a faixa com metragem mínima determinada de acordo com a largura dos cursos de água. Contudo, o referido código definiu que a delimitação de APP de reservatórios será definida conforme o caso, na ocasião do licenciamento ambiental.

A Resolução Conama n. 357 de 2005 dispõe sobre a classificação e enquadramento dos corpos hídricos, sendo relevante observar que as águas doces são classificadas em: classe especial; e classes de 1 a 4 . Dessa forma, para seleção da alternativa locacional e configuração espaçofuncional da AVDP, a referida classificação deve ser considerada, sendo mais apta a classe 4 e cada vez menos favorável quanto mais próxima da classe 1 .

Por fim, a Conama n. 369 de 2006 determina que, entre as APPs associadas aos recursos hídricos, somente aquelas ao longo de cursos d'água e ao redor de reservatórios constituem alternativas à implantação de AVDP e, entre as demais, apenas as de topo de morro e de restingas, quando não houver vegetação fixadora de dunas ou estabilizadora de mangues. Em complemento, esta norma estabelece como requisitos para a implantação da AVDP a aprovação pelo órgão ambiental competente de um projeto técnico que priorize a restauração e/ou manutenção das características do ecossistema local. Assim, determina ainda que esse projeto contemple medidas necessárias para: recuperação das áreas degradadas na APP; recomposição da vegetação com espécies nativas; mínima impermeabilização da superfície $(<5 \%)$; contenção de encostas e controle da erosão; adequado escoamento das águas pluviais; proteção de área da recarga de aquíferos; e proteção das margens dos corpos d'água. Os principais critérios relacionados a essa, demais normativas e aspectos antrópicos discutidos adiante, estão sistematizados na chave de decisão da Figura 1. 




FIGURA 1: Chave de decisão proposta para os fatores antrópicos e normativos.

FIGURE 1: Key decision proposal for anthropic and law factors.

\section{Fatores e processos ecológicos envolvidos no desempenho funcional das APPs}

Conforme proposto por Lucas (1982), os processos ecológicos foram organizados em dois grupos, sendo os quais definidos como processos geodinâmicos, isto é, aqueles em que predominam fatores geofísicos; e processos biodinâmicos, como aqueles nos quais predominam fatores biofísicos como desencadeadores de tais processos. Dessa forma, em observação ao recomendado por Santos (2004), foram considerados os fatores correlatos à geologia, pedologia; geomorfologia; hidrologia; climatologia; fauna ou zoologia; flora ou fitologia e sociedade ou antropologia, organizados conforme apresentado na Tabela 1 .

Quanto aos fatores geológicos (Tabela 2), deve-se considerar a presença de minerais, visto que tais bens são considerados de interesse social e utilidade pública, sendo recomendada consulta junto ao Departamento Nacional de Pesquisa
Mineral (DNPM, 2010).

Com relação à estrutura litológica, as cristalinas e metamórficas formadas, respectivamente, pela solidificação do magma e transformadas por intensa temperatura ou pressão, tendem a ser mais estáveis e resistentes que depósitos sedimentares (ROSS, 2008), proporcionado maior capacidade suporte e aptidão para a AVDP. Por fim, a ocorrência de falhas ou fraturas favorece a desintegração do material, tornando-o menos resistente a perturbações e à percolação de contaminantes (BRAGA, 2010), logo, constituem áreas a serem destinadas para fins predominantemente preservacionistas (Figura 2).

Quanto aos fatores pedológicos (Tabela 3 ), deve-se considerar que solos mais profundos possuem menor vulnerabilidade (SANTOS, 2004). Da mesma forma, em solos arenosos, são maiores os impactos decorrentes de sua impermeabilização, bem como os riscos de erosão e lixiviação de poluentes (LEPSCH, 2002). 
Finalmente, solos em que predominam a plasticidade, pegajosidade e friabilidade proporcionam menor capacidade suporte (IBGE, 2005), logo, maior risco à degradação comparativamente àqueles com maior dureza (Figura 3).

Referente aos fatores geomorfológicos (Tabela 4), tem-se que quanto maior a declividade

TABELA 1: Processos e fatores intervenientes no desempenho funcional da APP (Área de Preservação Permanente).

TABLE 1: Processes and factors affecting the functional performance of APP (Areas of Permanent Preservation).

\begin{tabular}{|c|c|c|}
\hline Processos & Temas & Principais Fatores \\
\hline \multirow{5}{*}{ 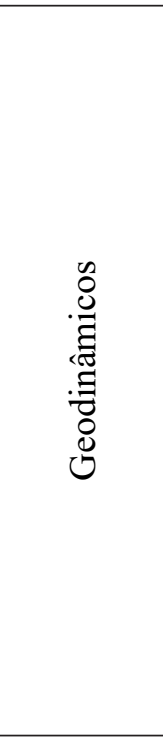 } & Geologia & $\begin{array}{l}\text { - Composição Mineral; } \\
\text { - Estrutura Litológica; e } \\
\text { - Integridade Estrutural; }\end{array}$ \\
\hline & Pedologia & $\begin{array}{l}\text { - Profundidade; } \\
\text { - Textura e Permeabilidade; e } \\
\text { - Consistência; }\end{array}$ \\
\hline & Geomorfologia & $\begin{array}{l}\text { - Declividade de encostas; } \\
\text { - Entalhamento do vale; e } \\
\text { - Morfologia; }\end{array}$ \\
\hline & Hidrologia & $\begin{array}{l}\text { - Qualidade e Quantidade; } \\
\text { - Padrão; e } \\
\text { - Condição; }\end{array}$ \\
\hline & Climatologia & $\begin{array}{l}\text { - Intensidade Pluviométrica; } \\
\text { - Amplitude térmica; e } \\
\text { - Pressão e Ventos; }\end{array}$ \\
\hline \multirow{3}{*}{ 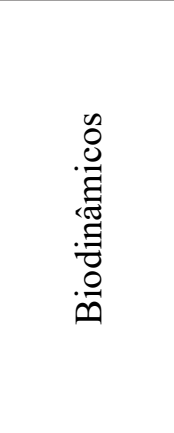 } & Fitologia & $\begin{array}{l}\text { - Bioma; } \\
\text { - Estágio sucessional / Formação; e } \\
\text { - Grau de Conectividade; }\end{array}$ \\
\hline & Zoologia & $\begin{array}{l}\text { - Biodiversidade; } \\
\text { - Distribuição e Habitat; e } \\
\text { - Endemismo; }\end{array}$ \\
\hline & Antropologia & $\begin{array}{l}\text { - Condição social; } \\
\text { - Ocupação atual; e } \\
\text { - Normatização. }\end{array}$ \\
\hline
\end{tabular}

TABELA 2: Classificação e aptidão dos fatores geológicos.

TABLE 2: Classification and suitability of geological factors.

\begin{tabular}{lll}
\hline \multicolumn{1}{c}{ Fatores } & \multicolumn{1}{c}{ Classes de Parâmetros } & \multicolumn{1}{c}{ Condição Avaliada } \\
\hline \multirow{2}{*}{ Interesse Mineral } & - Ausente & Aptidão Total \\
& - Presente & Restrição Absoluta \\
\hline \multirow{3}{*}{ Estrutura Litológica } & - Sedimentar & Aptidão Parcial \\
& - Cristalino & Aptidão Total \\
\hline \multirow{2}{*}{ Integridade Estrutural } & - Metamórfico & \\
& - Falhada / Fraturada & Aptidão Parcial \\
& - Intacta & Aptidão Total \\
\hline
\end{tabular}


TABELA 3: Classificação e aptidão dos fatores pedológicos.

TABLE 3: Classification and suitability of soil factors.

\begin{tabular}{|c|c|c|}
\hline Fatores & Classes de Parâmetros & Condição Avaliada \\
\hline \multirow{4}{*}{ Profundidade } & - muito rasa: $\leq 0,25 \mathrm{~m}$ & Restrição Absoluta \\
\hline & - rasa: $0,25-0,50 \mathrm{~m}$ & \multirow{2}{*}{ Aptidão Parcial } \\
\hline & - moderada: $0,50-1,0 \mathrm{~m}$ & \\
\hline & $\begin{array}{l}\text { - profunda: } 1,0-2,0 \mathrm{~m} \\
\text { - muito profunda: }>2,0 \mathrm{~m}\end{array}$ & Aptidão Total \\
\hline \multirow{5}{*}{ Textura / permeabilidade } & - muito argiloso & \multirow{2}{*}{ Aptidão Total } \\
\hline & - argiloso & \\
\hline & - médio & \multirow{2}{*}{ Aptidão Parcial } \\
\hline & - siltoso & \\
\hline & - arenoso & Restrição Absoluta \\
\hline \multirow{3}{*}{ Consistência } & - plástica / pegajosa & Restrição Absoluta \\
\hline & - friável & Aptidão Parcial \\
\hline & - dura / tenaz & Aptidão Total \\
\hline
\end{tabular}

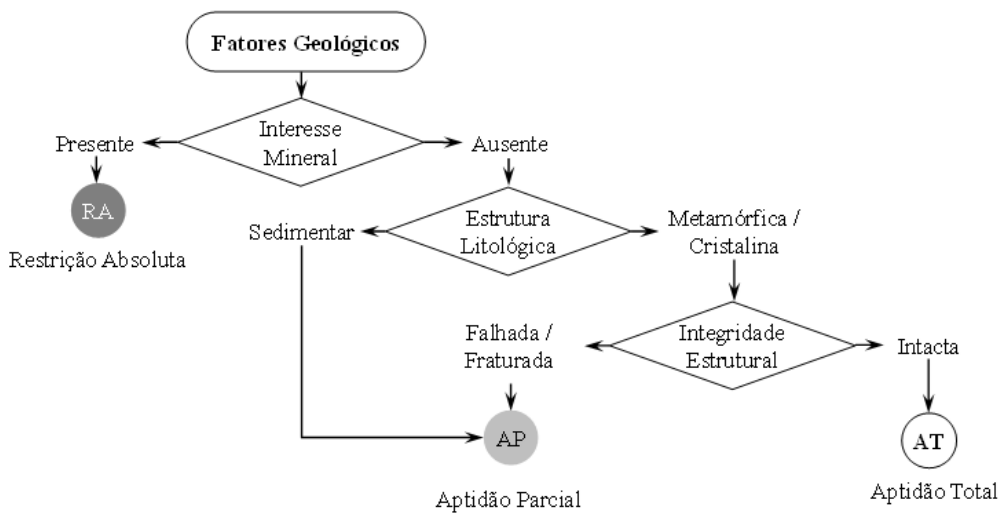

FIGURA 2: Chave de decisão proposta para os fatores geológicos.

FIGURE 2: Key decision proposal for geologic factors.

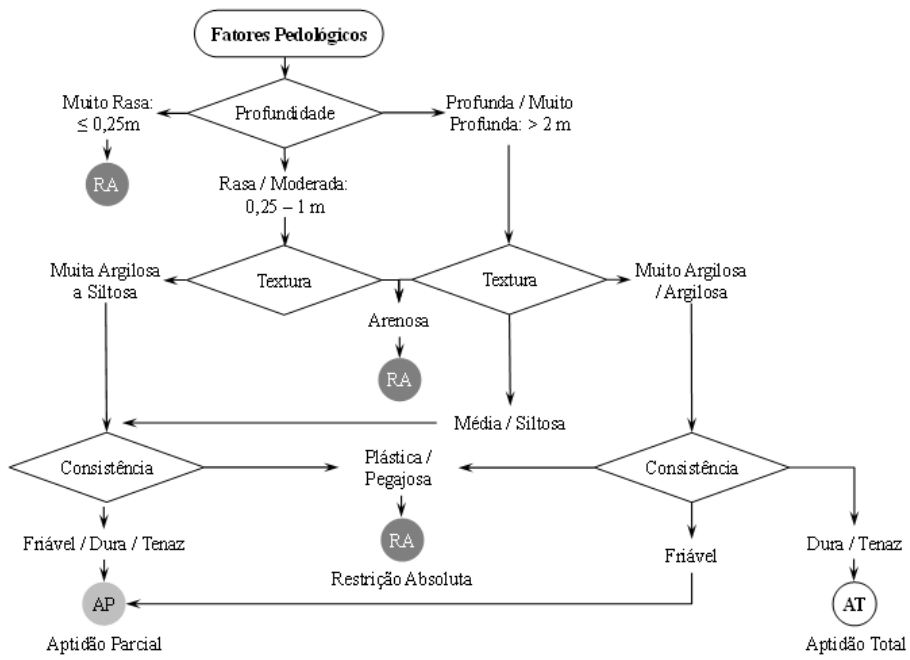

FIGURA 3: Chave de decisão proposta para os fatores pedológicos.

FIGURE 3: Key decision proposal for pedological factors. 
menor a capacidade suporte ao uso e ocupação da área (VIEIRA et al., 1988). Vales entalhados são menos sujeitos aos impactos de usos no entorno sobre a dinâmica fluvial e vegetação ripária comparativamente às planícies aluviais passíveis de inundações e variações no curso do canal (ROSS,

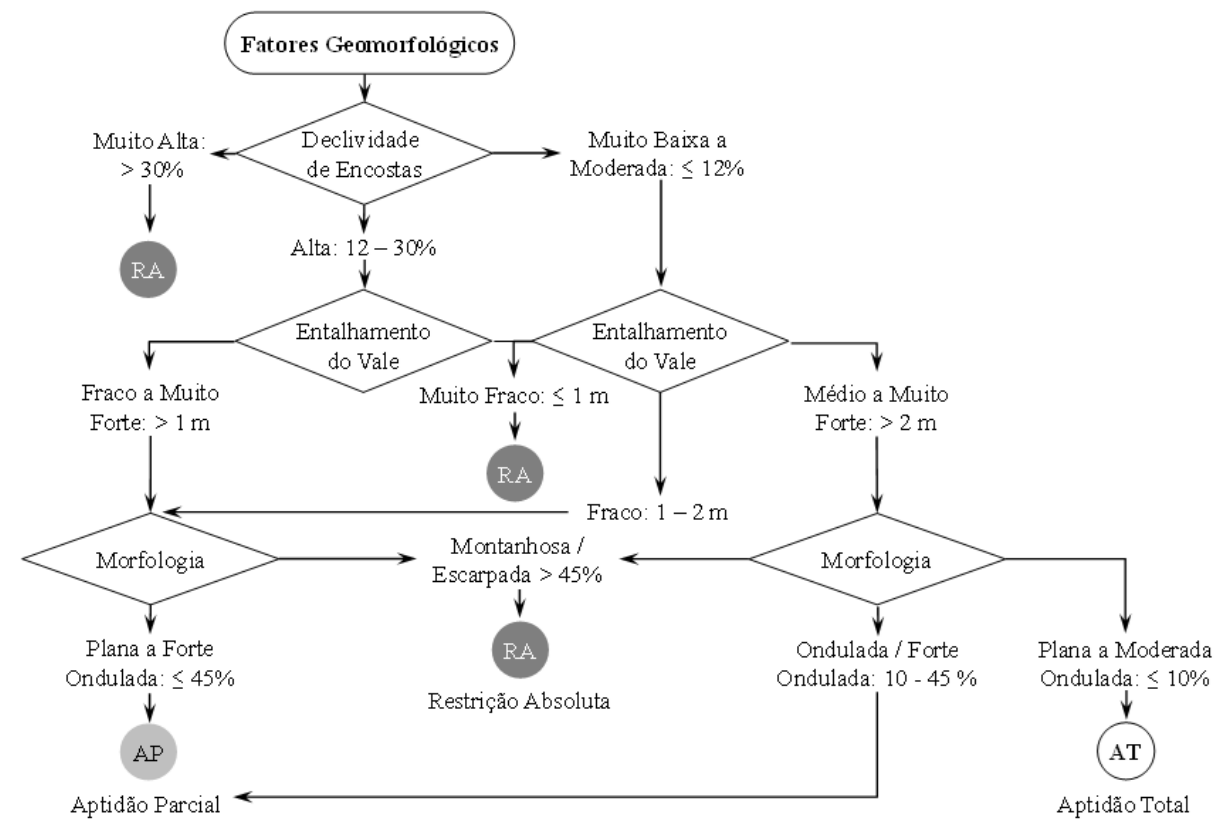

FIGURA 4: Chave de decisão proposta para os fatores geomorfológicos.

FIGURE 4: Key decision proposal for geomorphological factors.

TABELA 4: Classificação e aptidão dos fatores geomorfológicos.

TABLE 4: Key decision proposal for geomorphological factors.

\begin{tabular}{|c|c|c|}
\hline Fatores & Classes de Parâmetros & Condição Avaliada \\
\hline \multirow{5}{*}{ Declividade de encostas } & - muito baixa: $\leq 3 \%$ & \\
\hline & - baixa: 3 - $6 \%$ & Aptidão Total \\
\hline & - moderada: 6 - $12 \%$ & \\
\hline & - alta: $12-30 \%$ & Aptidão Parcial \\
\hline & - muito alta: > $30 \%$ & Restrição Absoluta \\
\hline \multirow{4}{*}{ Entalhamento do vale } & - muito fraco: $\leq 1 \mathrm{~m}$ & Restrição Absoluta \\
\hline & - fraco: $1-2 \mathrm{~m}$ & Aptidão Parcial \\
\hline & - médio: $2-4$ m & \\
\hline & $\begin{array}{l}\text { - forte: } 4-8 \mathrm{~m} ; \\
\text { - muito forte: }>8 \mathrm{~m}\end{array}$ & Aptidão Total \\
\hline \multirow{6}{*}{ Morfologia } & - plana: $0-2 \%$ & \\
\hline & - suave ondulada: 2 - $5 \%$ & Aptidão Total \\
\hline & - moderado-ondulada: 5 - $10 \%$ & \\
\hline & - ondulada: $10-15 \%$ & Antidão Parcial \\
\hline & - forte ondulada: $15-45 \%$ & Aptidao rarcial \\
\hline & $\begin{array}{l}\text { - montanhosa: } 45-70 \% \\
\text { - escarpada: }>70 \%\end{array}$ & Restrição Absoluta \\
\hline
\end{tabular}


TABELA 5: Classificação e aptidão dos fatores hidrológicos.

TABLE 5: Classification and suitability of hydrological factors.

\begin{tabular}{lll}
\hline \multicolumn{1}{c}{ Fatores } & \multicolumn{1}{c}{ Classes de Parâmetros } & \multicolumn{1}{c}{ Condição Avaliada } \\
\hline \multirow{2}{*}{ Qualidade } & Ótima & Restrição Absoluta \\
& Boa & Aptidão Parcial \\
& $\begin{array}{l}\text { Regular } \\
\text { Ruim } \\
\text { Péssima }\end{array}$ & \\
& Meandrante & Aptidão Total \\
\hline \multirow{2}{*}{ Padrão } & Dentrítico & Restrição Absoluta \\
& Paralelo & Aptidão Total \\
\hline \multirow{3}{*}{ Condição } & Canal / Reservatório natural & Aptidão Parcial \\
& Canal / Reservatório artificial & Aptidão Total \\
& Canal artificial fechado & Restrição Absoluta \\
\hline
\end{tabular}

1994). Por sua vez, relevos mais acidentados tendem à maior ocorrência de processos transformadores da paisagem que aqueles mais planos(TRICART, 1977), os quais podem ser considerados relativamente mais estáveis (Figura 4).

No que se relaciona aos fatores hidrológicos (Tabela 5), corpos d'água com melhor qualidade (mais preservados) devem ter suas funções ecológicas e a proteção enquanto manancial de abastecimento priorizadas em relação às funções sociais de lazer, recreação ou paisagismo (CETESB, 2011).

Complementarmente, considera-se que canais meandrantes são dinâmicos, com frequentes alterações no curso e alagamentos de áreas adjacentes (HOWARD, 1945 apud SANTOS, 2004), logo, constituem restrições à implantação de AVDP. Nesse cenário, vale ainda ressaltar que canais fechados não geram APP, logo, não representam alternativa para AVDP (SÃO PAULO, 2010). Por sua vez, canais artificiais, isto é, cursos d'água com seção e/ou traçado alterado ou modificado (DAEE, 2005), bem como os reservatórios artificiais, possuem maior aptidão à AVDP com fins sociais, enquanto que naqueles em condições naturais devem prevalecer as funções ecológicas (Figura 5).

Quanto aos fatores climáticos, as áreas com maior intensidade pluviométrica (pluviosidade média anual / duração do período chuvoso em meses) possuem maior risco de perda de solo (CREPANI et al., 2001), logo, com menor aptidão à AVDP. No que se relaciona à amplitude térmica, à pressão e aos ventos não foram encontradas referências na literatura técnica para fundamentar

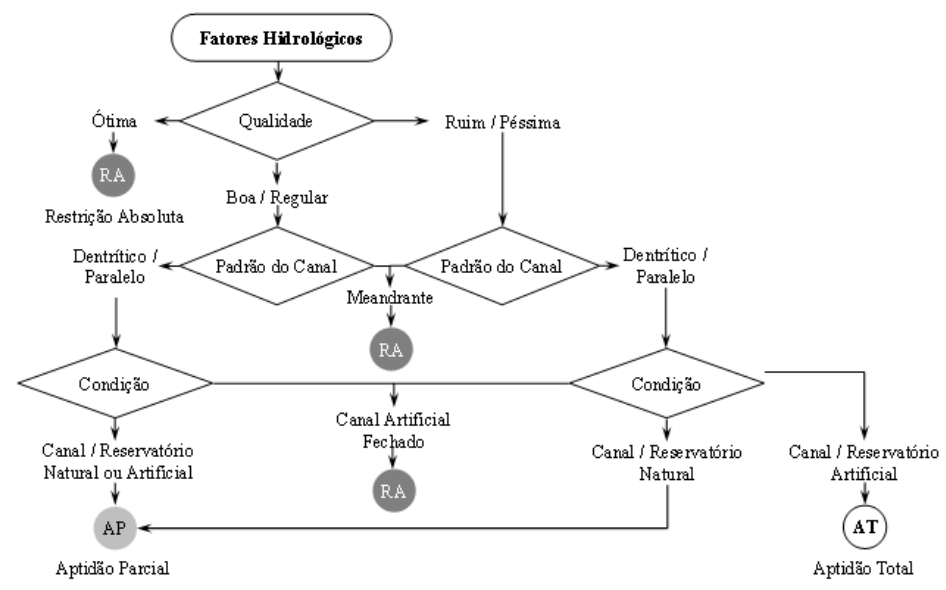

FIGURA 5: Chave de decisão proposta para os fatores hidrológicos.

FIGURE 5: Key decision proposal for hydrological factors. 
TABELA 6: Classificação e aptidão dos fatores climatológicos.

TABLE 6: Classification and suitability of climatological factors.

\begin{tabular}{cll}
\hline \multicolumn{1}{c}{ Fatores } & \multicolumn{1}{c}{ Classes de Parâmetros } & \multicolumn{1}{c}{ Condição Avaliada } \\
\hline & Baixa: $\leq 175 \mathrm{~mm} / \mathrm{mês}$ & Aptidão Total \\
Intensidade pluviométrica & Média: $175-300 \mathrm{~mm} / \mathrm{mês}$ & Aptidão Parcial \\
& Alta: $300-425 \mathrm{~mm} / \mathrm{mês}$ & Restrição Absoluta \\
& Muito alta: $>425 \mathrm{~mm} / \mathrm{mês}$ & \\
\hline
\end{tabular}

TABELA 7: Classificação e aptidão dos fatores fitossociológicos.

TABLE 7: Classification and fitness phytosociological study of the factors.

\begin{tabular}{lll}
\hline \multicolumn{1}{c}{ Fatores } & \multicolumn{1}{c}{ Classes de Parâmetros } & \multicolumn{1}{c}{ Condição Avaliada } \\
\hline \multirow{3}{*}{ Bioma } & Mata Atlântica & Aptidão Total \\
& Cerrado & Aptidão Parcial \\
& Ecótono & \\
& Primário & Restrição Absoluta \\
Estágio Sucessional & Secundário Avançado & \\
& Secundário Médio & \\
& Secundário Inicial & Aptidão Parcial \\
& Pioneiro / Ausente & Aptidão Total \\
\hline \multirow{3}{*}{ Grau de Conectividade } & Classes 1 e 2: baixo & Aptidão Total \\
& Classes 3 e 4: médio & Aptidão Parcial \\
& Classes 5 a 6: alto & Restrição Absoluta \\
& Classes 7 a 8: muito alto &
\end{tabular}

as recomendações em análise (Tabela 6).

Quanto aos fatores fitossociológicos (Tabela 7), recomenda-se que nas áreas com fitofisionomias de cerrado (campo limpo, campo sujo, campo cerrado, cerrado SS e cerradão) sejam priorizadas as funções ambientais em virtude de sua complexidade ecológica (MAGALHÃES, 2010).

Quanto ao estágio sucessional, tem-se que áreas de floresta com vegetação primária e em estágios médio e avançado de regeneração secundária constituem restrições normativas à implantação de AVDP(BRASIL, 2006). Considerando a importância dos corredores ecológicos e do fluxo gênico de fauna e flora (FAPESP, 2008), áreas classificadas como de maior prioridade no incremento de conectividade devem ser recuperadas e conservadas (Figura 6).

No que tange aos fatores zoológicos (Tabela 8), valores relativos mais altos de biodiversidade, devem definir áreas prioritárias para conservação (BENSUSAN, 2006). Da mesma forma, o conhecimento quanto à presença de espécies ameaçadas de extinção ou endemismo requerem a proteção integral da área (PRIMACK e RODRIGUES, 2002), como sistematizado na Figura 7.

Considerando os fatores antrópicos e normativos (Tabela 9), em áreas com piores condições sociais (avaliação integrada de parâmetros socioeconômicos), recomenda-se a implantação de AVDP com maior aptidão para o desempenho de funções dessa natureza (social) (BVS, 2011).

Complementarmente, deve ser avaliada a demanda por lazer na vizinhança. Se não houver espaços para recreação no entorno da APP avaliada, recomenda-se a implantação de AVDP com aptidão total e, em contrário, parcial. Em caso de prévia ocupação em APP, nos casos em que são atendidos os requisitos para regularização fundiária sustentável, esta deve ser priorizada (BRASIL, 2006).

Quanto ao domínio da área, são indisponíveis para a implantação de AVDP, as APP situadas em áreas particulares antes de prévia desapropriação para fins de utilidade pública (BRASIL, 1934). No que diz respeito ao enquadramento das águas, 
deve-se considerar que a classe especial restringe atividades recreativas e as classes 1 e 2 preveem apenas aquelas de contato primário (BRASIL,
2005).

Com relação ao zoneamento urbano, ressalva-se que os casos excepcionais de intervenção

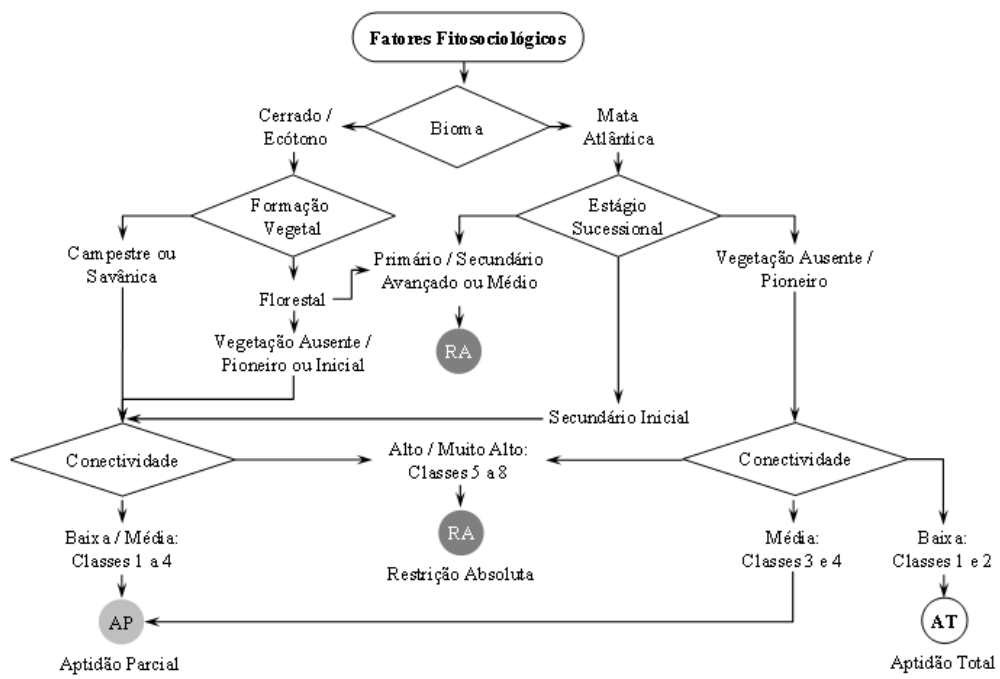

FIGURA 6: Chave de decisão proposta para os fatores fitossociológicos.

FIGURE 6: Key decision proposal for phytossociological factors.

TABELA 8: Classificação e aptidão dos fatores zoológicos.

TABLE 8: Classification and fitness zoological study of the factors.

\begin{tabular}{lll}
\hline \multicolumn{1}{c}{ Fatores } & \multicolumn{1}{c}{ Classes de Parâmetros } & \multicolumn{1}{c}{ Condição Avaliada } \\
\hline \multirow{3}{*}{ Biodiversidade (fauna / flora) } & Baixo & Aptidão Total \\
& $\begin{array}{l}\text { Alto } \\
\text { Muito Alto }\end{array}$ & Aptidão Parcial \\
& Restrição Absoluta \\
\hline \multirow{2}{*}{ Endemismo / Ameaça } & Ocorrência & $\begin{array}{l}\text { Aptidão Total } \\
\text { Habitat }\end{array}$ \\
\hline \multirow{2}{*}{ Nota: não são encontrados na literatura técnica parâmetros pertinentes } \\
\end{tabular}

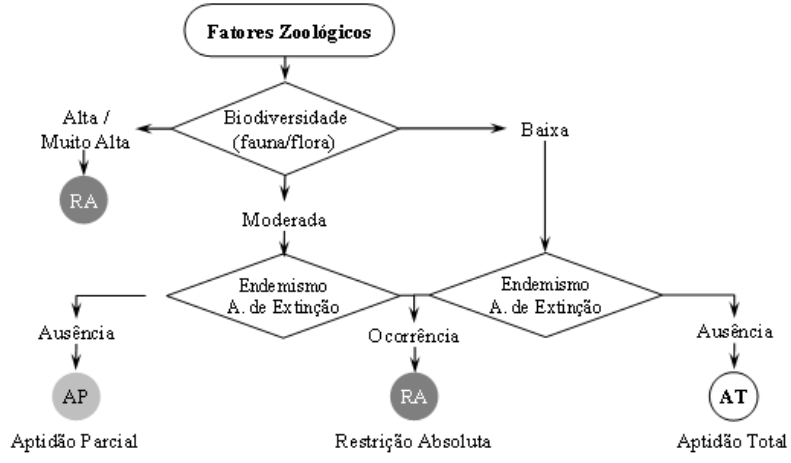

FIGURA 7: Chave de decisão proposta para os fatores zoológicos.

FIGURE 7: Key decision proposal for zoo factors. 
TABELA 9: Classificação e aptidão dos fatores antrópicos / normativos.

TABLE 9: Classification and ability of human / law factors.

\begin{tabular}{lll}
\hline \multicolumn{1}{c}{ Fatores } & Classes de Parâmetros & \multicolumn{1}{c}{ Condição Avaliada } \\
\hline \multirow{2}{*}{ Condição social } & Boa & Aptidão Parcial \\
& Moderada & \\
& Ruim & \\
& Péssima & Aptidão Total \\
\hline \multirow{2}{*}{ Demanda por lazer } & Sim & \\
\hline & Não & Aptidão Total \\
Ocupação na APP & Regular / Regularizável & Aptidão Parcial \\
\hline \multirow{2}{*}{ Domínio } & Irregular & Restrição Absoluta \\
& Ausente & Aptidão Total \\
\hline \multirow{2}{*}{ Enquadramento das águas } & Público & Aptidão Total \\
& Particular & Restrição Absoluta \\
\hline Zona Municipal & Classe especial & Restrição Absoluta \\
& Classes 1 e 2 & Aptidão Parcial \\
Sobreposição com APP restritivas & Classes 3 e 4 & Aptidão Parcial \\
\hline & Área Rural & Restrição Absoluta \\
& Área Urbana & Aptidão Total \\
\hline
\end{tabular}

em APP para uso alternativo, tal como a implantação de AVDP, aplicam-se somente às áreas urbanas consolidadas (BRASIL, 2006).

Por fim, deve-se ainda considerar que na APP de nascentes, veredas, encostas, escarpas, bordas de tabuleiros e chapadas, manguezal, duna, restinga, altitude superior a $1.800 \mathrm{~m}$ é restringida a implantação de AVDP (BRASIL, 2006). Estes critérios foram sistematizados na chave de decisão junto aos fatores normativos apresentados anteriormente.

Portanto,combasenoexpostoeconsiderando que se trata de as áreas de preservação permanente, propõe-se que a análise integrada destes critérios se baseie na condição mais restritiva, visando priorizar suas funções ecológicas, bem como a proteção dos recursos ambientais associados. Assim, conforme as chaves de decisão apresentadas, recomenda-se que seja considerada:

- aptidão total somente se todos os critérios forem avaliados nesta condição;

- restrição absoluta mesmo se apenas um único critério indicar está condição; e

- aptidão parcial se um ou mais critérios indicar esta condição e não houver qualquer restrição absoluta.

\section{CONCLUSÕES}

A urbanização pode ser considerada uma consequência inerente ao crescimento e modernização das cidades, bem como para o atendimento de demandas sociais básicas de sua população. Contudo, torna-se fundamental instituir instrumentos que possibilitem controlar a forma acelerada e desordenada que, não raro, tem regido tal processo.

Com esta finalidade, as áreas de preservação permanente constituem um instrumento importante para proteção e recuperação da qualidade hídrica, em especial no meio urbano por concentrar grande proporção das fontes de perturbação decorrentes das atividades antrópicas. Contudo, a complexidade urbana requer uma compreensão sistemática sobre o desempenho e finalidade das áreas de preservação no contexto das cidades, sobretudo, sobre os fatores intervenientes e a configuração espaço-funcional mais apropriada, de acordo com os critérios e respectivas condições avaliadas. Para isso, a partir do estudo das normas aplicáveis, bem como da literatura técnica, foi possível identificar os principais fatores de influência sobre o amparo e desempenho funcional dessas áreas. 
Assim, os resultados indicam que as áreas verdes como uso alternativo do solo em APP podem constituir uma solução adequada para gestão de corpos hídricos urbanos, desde que condicionadas às práticas conservacionistas necessárias ao desempenho de suas funções, tanto ecológicas, como sociais. Dessa forma, conclui-se que este trabalho pôde contribuir com um sistema de suporte à decisão que possibilita uma análise caso a caso para implantação criteriosa das áreas verdes, como instrumento para gestão estratégica dos recursos hídricos urbanos.

\section{REFERÊNCIAS BIBLIOGRÁFICAS}

AMERICAN NATIONAL STANDARDS INSTITUTE. ANSI. Flowchart symbols and their usage in information processing. New York: ANSI, 1970, $21 \mathrm{p}$.

BENSUSAN, N. Conservação da biodiversidade em áreas protegidas. Rio de Janeiro: FGV, 2006, $176 \mathrm{p}$.

BEJAMIN, A. H. Introdução ao Direito Ambiental Brasileiro. Revista de Direito ambiental. Rio de Janeiro, n.14, p. 46-58, 1999.

BONONI, V. L. R. Controle ambiental de áreas verdes. In: PHILIPPI JUNIOR, A.; ROMÉRO, M. A. BRUNA, G. C. Curso de gestão ambiental. $2 \mathrm{ed}$. Barueri: Manole, Cap. 6. 214-255p.. 2006, 1045p. BRAGA, A. Critérios de escoamento. Rio de Janeiro: Pontífice Universidade Católica, 2010, $15 \mathrm{p}$.

BIBLIOTECA VIRTUAL EM SAÚDE. BVS. Descritores em ciência da saúde. Disponível em: < http://decs.bvs.br/cgi-bin/ wxis 1660 .exe/decsserver/? Isis Script $=$../cgibin/decsserver/ decsserver.xis\&previous page $=$ homepage $\&$ task $=$ exact_term \&interface language $=$ p \&search_language $=$ p $\&$ search exp $=$ Condi $\% E 7 \% F 5 e s \% 20$ Sociais $>$. Acesso: 09 fev. 2011.

BRASIL. Secretaria de Recursos Hídricos eAmbiente Urbano. SRHU/MMA. Termo de referencia para contratação de assessoria à SRHU/MMA na elaboração de metodologia de inserção de questões ambientais na gestão urbana. 2009. Disponível em: <http:/ /www.mma.gov.br/sitio/index.php?ido= conteúdo.monta\&idestrutura $=125 \&$ idconteudo $=8151>$. Acesso em: 05 jun. 2009. BRESSANE, A. Sistema de suporte à decisão para a gestão de áreas verdes de domínio público em áreas de preservação permanente de corpos hídricos urbanos. 2011. 127 f. Dissertação (Mestrado em Engenharia Urbana) - Universidade Federal de São Carlos.

COMPANHIA AMBIENTAL DO ESTADO DE SÃO PAUlO. CETESB. Qualidade da água. Disponível em: < http://www.cetesb.sp.gov.br/ agua/ águas-superficiais/108-índices-de-qualidadedas-águas $>$. Acesso em: 18 jan. de 2011.

CREPANI, E. et al. Sensoriamento remoto e geoprocessamento aplicados ao zoneamento ecológico econômico e ao ordenamento territorial. São José dos Campos: INPE, 2001, 103 p.

DEPARTAMENTO DE ÁGUAS E ENERGIA ELÉTRICA. DAEE. Guia prático para projetos de pequenas obras hidráulicas. São Paulo: DAEE, 2005, $112 \mathrm{p}$.

DEPARTAMENTO NACIONAL DE PRODUÇÃO MINERAL. DNPM. Sistema que reúne informações sobre os Processos de Mineração. Disponível em: < http://www.dnpm.gov.br / conteudo.asp? IDSecao $=62 \&$ IDPagina $=40>$. Acesso em: 20 nov. 2010.

FRIEDRICH, D. O parque linear como instrumento de planejamento e gestão das áreas de fundo de vale urbanas. 2007. 273fls. Dissertação (Mestrado em Planejamento Urbano e Regional). Universidade Federal do Rio Grande do Sul, Porto Alegre/RS, 2007.

FUNDAÇÃO DE AMPARO À PESQUISA DO ESTADO DE SÃO PAULO. FAPESP. Conhecimento e uso sustentável da biodiversidade brasileira: o Programa Biota-FAPESP. São Paulo: FAPESP, 2008, 204p.

INSTITUTO BRASILEIRO DE GEOGRAFIA ESTATÍSTICA. IBGE. Manual Técnico de Pedologia. 2 ed. Rio de Janeiro: IBGE, 2005, 300 p. LEPSCH, F. I. Formação e conservação dos solos. São Paulo: Oficina de textos, 2002, 178p.

LOBODA, C. R. Estudo das áreas verdes urbanas de Guarapuava (PR). 2003. 160fls. Dissertação (Mestrado em Geografia) Universidade Estadual de Maringá, Maringá/PR, 2003.

LUCAS, M. L. G. Arquitetura paisagística no planejamento físico-territorial. Porto Alegre: Gg Edições Técnicas, 1982, 102p.

MACHADO, P. A. L. Direito Ambiental Brasileiro. 19ed. São Paulo: Malheiros, 2011, 1224 p.

MAGALHÃES, T. A. L. PRINCÍPIO DA PRECAUÇÃO E EVOLUÇÃO DA RESPONSABILIDADE CIVIL. São Paulo: Quartier Latin, 2010, 251 p. 
MORERO, A. M.; SANTOS, R. F.; FIDALGO, E. C. C. Planejamento Ambiental de Áreas Verdes: Estudo de Caso em Campinas-SP. Rev. Inst. Flor., v.19, n.1, p. 19-30, 2007.

NUCCI, J. C.; CAVALHEIRO, F. Cobertura vegetal em áreas urbanas: conceito e método. GEOUSP, São Paulo/SP, n.8, 1997, 29-36p.

PRIMACK, R. B.; RODRIGUES, E. Biologia da conservação. Londrina: Efraim, 2002, $328 \mathrm{p}$.

ROSS, J. L. S. (org.) Geografia do Brasil. 6 ed. São Paulo: Edusp, 2008, 549 p.

ROSS, J. L. S. (org.). Análise empírica da fragilidade dos ambientes naturais e antropizados. In: Revista do Departamento de Geografia. São Paulo, n. 8, p. 63-74, 1994.

SANTOS, F. S. Planejamento ambiental: teoria e prática. São Paulo: Oficina de Textos, 2004, 183 p.

SARAIVA, M. G. A. N. O Rio como Paisagem: gestão de corredores fluviais no quadro do ordenamento do território. Liboa: Fundação
Calouste Gulbenkian/Fundação para Ciência e Tecnologia, 1999, 512p.

SÃO PAULO (Estado). Tribunal de Justiça do Estado de São Paulo. TJSP. Processo n. 411.7775/5-00 do TJSP. Disponível em: $<$ http://esaj.tj.sp. gov.br/cjsg/resultadoCompleta.do >. Acesso em: 02 fev. 2010.

SILVA, R. A.; SOUZA, A. M. G. F.; LOUREIRO, C. M. F. Uso e ocupação do solo versus problemas ambientais. In: BRAGA, R.; CARVALHO, P. F. (org.). Perspectivas de gestão ambiental em cidades médias. Rio Claro-SP: UNESP, 2001, 138 p.

TRICART, J. Ecodinâmica. Rio de Janeiro: IBGE/ SUPREN, 1977, 91p.

VICTORINO, V. I. Uma Visão Histórica dos Recursos Hídricos na Cidade de São Paulo. Revista Brasileira de Recursos Hídricos. v.7, n.1, 2002, 51-68p.

VIEIRA, L. S.; SANTOS, P. C. T; VIEIRA, M. N. F. Solos: propriedades, classificação e manejo. Brasília: MEC/ABEAS, 1988, 9 p. 